Instructions for authors, subscriptions and further details:

http://brac.hipatiapress.com

\title{
La Geometría como Esquema Profundo de la Obra Artística y su Relación con la Evolución de Nuestra Consciencia.
}

Belén León-Río ${ }^{1}$

1) Facultad de Bellas Artes, Universidad de Sevilla. España

Date of publication: February $3^{\text {rd }}, 2018$

Edition period: February 2018 - June 2018

To cite this article: León-Río, B. (2018). La Geometría como Esquema Profundo de la Obra Artística y su Relación con la Evolución de Nuestra Consciencia. Barcelona, Research, Art, Creation, 6(1) 42-71. doi: 10.17583/brac.2018.2360

To link this article: http://dx.doi.org/10.17583/brac.2018.2360

PLEASE SCROLL DOWN FOR ARTICLE

The terms and conditions of use are related to the Open Journal System and to Creative Commons Attribution License (CC-BY). 
BRAC - Barcelona Research Art Creation. Vol. 6 No. 1, February 2018, pp. 42-71

\section{Geometry as a Deep Scheme of the Artistic Work and its Relationship with the Evolution of Our Consciousness}

Belén León del Río.

Universidad de Sevilla. (Spain)

(Received: 20 October 2016; Accepted: 22 October 2016; Published: 3 February 2018)

\section{Abstract}

The artist possesses the ability to perceive the absolute and permanent relations contained in the transitional and changing forms of our interior and exterior nature. The archetype, movement and rhythm describe fundamental energies that would be part of our deepest essence, translating into symbols. Thus, in the compositions of artistic works exist a geometry that would correspond to a symbolic of the whole, which already applied to figures or schemes since ancient times and in the most diverse religions. In this article we will see how the artist would be able to transcribe through the immaterial archetypes and abstract geometry that would hide in the realm of nature, full of proportions and symmetries would be reflected through the plastic experience. The symbol takes both the creator and the viewer to have an experience that would produce a broader knowledge and can study the psychological processes of artistic activity through these archetypes.

Keywords: archetype, unconscious, symbol, geometry, proportion 
BRAC - Barcelona Research Art Creation. Vol. 6 No. 1, February 2018, pp. 42-71

\section{La Geometría como Esquema Profundo de la Obra Artística y su Relación con la Evolución de Nuestra Consciencia}

Belén León del Río.

Universidad de Sevilla. (España)

(Recibido: 20 octubre 2016; Aceptado: 22 octubre 2016; Publicado: 3 febrero 2018)

\section{Resumen}

El artista poseería la capacidad de percibir las relaciones absolutas y permanentes, contenidas en las formas transitorias y cambiantes de nuestra naturaleza tanto interior como exterior. El arquetipo, el movimiento y el ritmo describirían energías fundamentales que formarían parte de nuestra esencia más profunda, traduciéndose en símbolos. Así en las composiciones de las obras artísticas existiría una geometría que se correspondería con una simbólica de la totalidad, que ya se aplicaba a figuras o esquemas desde la antigüedad y en las religiones más diversas. En este artículo veremos como el artista, sería capaz de transcribir mediante arquetipos la geometría inmaterial y abstracta que se escondería en el reino de la naturaleza, llena de proporciones y simetrías que se reflejaría a través de la experiencia plástica. El símbolo llevaría tanto al creador como al espectador a tener una vivencia que produciría un conocimiento más amplio, pudiendo estudiar los procesos psicológicos de la actividad plástica a través de estos arquetipos.

Palabras clave: arquetipo, inconsciente, símbolo, geometría, proporción 


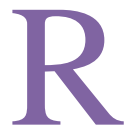

obert Lawlor afirma cómo actualmente estaríamos presenciando en el campo de las ciencias una tendencia general a abandonar el supuesto de que la naturaleza fundamental de la materia sólo se podía estudiar desde el punto de vista de la sustancia (como las partículas o cuantos) a favor del concepto, de que la naturaleza fundamental de la materia sólo se puede conocer a través de la organización subyacente de sus formas u ondas:

Tanto nuestros órganos de percepción como el mundo de los fenómenos que percibimos parecen comprenderse mejor como sistemas de puros esquemas, o como estructuras geométricas de formas y proporción. De ahí que cuando muchas de las culturas antiguas optaron por examinar la realidad a través de las metáforas de la geometría y la música (la música en tanto que estudio de las leyes proporcionales de la frecuencia de sonidos), ya estaban muy de cerca de las posiciones de nuestra ciencia más contemporánea. (Lawlor, 1993, p. 4)

A. Daniélou dice como las grandes culturas espirituales del pasado se basaron en el intercambio entre vibraciones y formas, poniendo de ejemplo desde los átomos hasta el universo, donde cada uno de los movimientos cósmicos poseería un tempo, un ritmo, una periodicidad, pudiéndose comparar a la vibración, y por tanto a un sonido que expresaría su naturaleza. Este autor señala que, aunque no todas las vibraciones son perceptibles a nuestros oídos, las relaciones entre las vibraciones pueden compararse a las relaciones entre frecuencias audibles. Así como todos los átomos pueden considerarse como las formas de una energía que se expresaría en un ritmo, también todas las sustancias estarían caracterizadas por una relación particular de ritmos que se podrían representar mediante una relación de sonidos. Para A. Daniélou esta similitud entre las relaciones de los sonidos y, por otra parte, las formas y las sustancias de la naturaleza, es como se harían posibles el lenguaje y la música. En su obra Traité de musicologie comparée dice: "Los sonidos puros, los sonidos inmateriales que constituyen la naturaleza profunda de las cosas y que Kabir llama <su música inaudible>, se pueden percibir mediante instrumentos más sutiles que nuestros oídos" (como se citó en Lawlor, 1993, p. 89.).

La geometría trataría de la forma pura, reconstruyendo el desarrollo de cada forma a partir de otra anterior, haciendo así visible el misterio creativo en toda su esencia. R. Lawlor dice como la geometría siempre se ha ocupado de estudiar el orden espacial mediante la medición de las relaciones entre las 
formas. En la educación clásica la geometría, la aritmética y la astronomía constituían las principales disciplinas intelectuales de la educación clásica. A esto se unía el "quadrivium", el estudio de la armonía y la música. De esta manera el objetivo de la educación era convertir al discípulo en un canal a través del cual la "tierra" o nivel de la forma manifestada podía recibir lo abstracto es decir la vida cósmica de los cielos:

La práctica de la geometría era una aproximación a la manera en que el universo se ordena y se sustenta. Los diagramas geométricos pueden ser contemplados como momentos de inmovilidad que revelan una continua e intemporal acción universal generalmente oculta a nuestra percepción sensorial. De esta manera, una actividad matemática aparentemente tan común puede convertirse en una disciplina para el desarrollo de la intuición intelectual y espiritual. (Lawlor, 1993, p. 6)

G. Dorfles actualiza la expresión platónica "simetría dinámica" usada en el Teeteto, explicando cómo el ritmo se acercaría a la simetría, pero no como algo estático y regular, sino como una simetría dinámica, rítmica y espacio temporal, siendo el ritmo junto con las proporciones y el equilibrio una de las constantes principales, en la en las que reposaría el arte:

El hecho de que el espacio como el tiempo se subdivida y se distribuya proporcionalmente en menudos fragmentos homólogos y recurrentes, me parece una prueba más de la identidad topo-cronológica considerada como unívoco médium en cuyo interior se desarrollan los fenómenos de cadencia y armonía que constituyen la base de todo arte, lo mismo musical que visual. Toda división pues, entre artes rítmicas (música, poesía, danza) y artes pláticas (arquitectura, pintura, escultura) desaparece pues, al menos desde ese punto de vista. (Dorfles, 1986, p. 60)

Adolf von Hildebrand, escultor neoclásico decía que si intentábamos analizar nuestras imágenes mentales para descubrir sus constituyentes primarios, encontraremos que se componen de datos sensorios derivados de la visión y de recuerdos de tacto y del movimiento, analiza en su obra $E l$ problema de la forma en el arte figurativo de 1893, haciendo una apelación a la psicología de la percepción como ya hiciera Konrad Fiedler quien decía que "incluso la más simple impresión sensoria, que parece sólo materia prima para las operaciones de la mente, es ya un hecho mental, y lo que llamamos el mundo exterior es en realidad el resultado de un proceso psicológico complejo" (Gombrich, 2002, p. 13). 
Los fisiólogos Hubel y Wiesel descubrieron en sus estudios del cerebro visual que las células respondían selectivamente a las líneas que tendrían una orientación concreta, considerando que estas células serían los componentes fisiológicos básicos de la generación neuronal de las formas, aunque según Zeki:

(...) nadie sabe cómo se construyen neurológicamente formas complejas a partir de células que responden a lo que consideramos que son los componentes de todas las formas. En cierto sentido, nuestra búsqueda y nuestra conclusión no son diferentes de las de Mondrian, Malevich y otros. (Como se citó en Kandel, 2013, p. 290)

Zeki pone de ejemplo a Mondrian que consideraba la línea recta como la forma universal, siendo el componente básico de las formas más complejas, mientras que los fisiólogos creerían que las células que responderían específicamente a lo que Mondrian y otros artistas consideraban que sería la forma universal, serían las mismas que, como componentes básicos, permitirían al sistema nervioso representar formas más complejas: "Me resisto a creer que la relación entre la fisiología de la corteza visual y las creaciones de los artistas sea totalmente fortuita" (como se citó en Kandel, 2013, p. 290).

L. Duch llama la atención sobre el hecho de que diferentes sistemas de escritura implicarían correlativamente diversas formas de lectura: "Se ha hecho notar, por ejemplo, que el desciframiento de los ideogramas ponía en movimiento unos sectores del cerebro humano diferentes de los que intervienen en el caso de la escritura alfabética o silábica" (Duch, 2003, p. 157).

E. Pérez de Carrera señala como hemos olvidado los orígenes de la configuración actual de nuestra razón, señalando como el hombre viene del pictograma, pasando luego al fonema, del fonema semiestructuraría el holograma y después pasaría al rastro, diciendo como cada idioma definiría fonéticamente e incluso ideológicamente, una visión distinta del mundo aparencial, esto ocurriría igualmente con la poesía, el ritmo o el movimiento y los matices de la conducta, cada persona tendría su propio idioma, porque cada significación viviría en un ideograma distinto y toda palabra desarrollaría el dibujo de un pictograma único en cada cerebro:

Cada forma energética tiene sus letras, sus sonidos, sus colores, sus dibujos mágicos, sus sonidos esenciales, sus movimientos modélicos y sus ritmos, y su voluntad y su destino como dones y ofrendas sagrados que deben iluminar el camino hacia el espíritu. (Pérez de Carrera, 2004, p. 45) 
Para Kandinsky la letra produciría un efecto que el artista calificaría de doble. Primero la letra actuaría como un símbolo que tendría un propósito y segundo actuaría como una forma y después como resonancia interna de esa forma, que sería autosuficiente e independiente. "Para nosotros es importante que ambos efectos no son recíprocos, que el primero es externo y el segundo tiene un valor interno" (como se citó en Chipp, 1995, p. 181).

Sri Aurobindo afirma como la mente emergió en el hombre a partir de las actividades vitales y sensoriales, edificándose su intelecto sobre una base de "asociaciones-de-los-sentidos", de la misma forma el uso intelectual del lenguaje se desarrolló, según su ley natural, a partir de lo sensorial y lo emocional. Así tras haber consistido originariamente en emisiones vocales con sentido vago y potencial, las palabras evolucionaron hasta convertirse en los símbolos fijos de una idea intelectual precisa. En sus comienzos, los "sonidos-de-lenguaje", no servían para expresar lo que llamamos ideas, sino que esos sonidos eran más bien los equivalentes vocales de valores sensoriales y emotivos fundamentales. "Fueron los nervios y no la inteligencia quienes generaron la palabra" (Aurobindo, 2001, p. 69).

E. H. Gombrich señala como el ser humano tiene tendencia a sondear tanto el mundo real como sus representaciones con una hipótesis de regularidad que no es abandonada a no ser que sea refutada, diciendo que la variedad del mundo visible se reduce en los esquemas que suelen ser descritos como imágenes conceptuales, a las que define como modelos mínimos de los objetos que se pretenden representar. Este autor llama la atención sobre el hecho de que el esquema mínimo es construido antes de ser modificado o corregido, e incluso antes de comparárselo con la realidad, de manera que "hacer viene antes que comparar" (Gombrich, 1999, p. 5), explicando como el tanteo vendría antes que la captación y la búsqueda vendría antes que la visión: "En contraste con cualquier teoría del estímulo-respuesta desearía señalar la necesidad de contemplar el organismo como un agente activo que busca el entorno, no a ciegas ni al azar, sino guiado por su inherente sentido del orden" (Gombrich, 1999. p. 5). E. H. Gombrich indica como su creencia de "sentido de orden" procede de la teoría de la percepción de la obra Objetiva Knowledge de K. Popper que dice: "Fue primero en animales y niños, pero más tarde también en adultos, donde observé la inmensamente poderosa necesidad de regularidad, la necesidad que les mueve a buscar regularidades" (como se citó en Gombrich, 1999, p. 1).

D. Mitchinson dice como Henry Moore concentraba en su obra, a las fuerzas de la naturaleza hasta condensarlas en formas aprisionadas en dimensiones geométricas. Esto puede observarse en el modo en que investiga 
la forma escultórica, extrayendo sólidos geométricos de las formas naturales. Era la composición de los volúmenes abstractos y no la representación de los aspectos externos de la realidad lo que le interesaba. Tendía a encerrar cada uno de los elementos de una figura o de un grupo en bloques dinámicamente interconectados, delimitando mediante una jaula espacial, una profundidad geométrica dentro de la cual tenía que circunscribirse la escultura como un centro o núcleo irradiando energía encadenada. Establecía proporciones tridimensionales para "componer en cubo" como decían sus notas. Buscaba una espacialidad relacionada con el volumen que lo pudiese encerrar dentro de límites precisos y aumentar así su vitalidad interior. Henry Moore decía sobre esta forma de trabajar su escultura: "La fuerza, el poder, se hace con formas que tiran o empujan desde dentro" (como se citó en Mitchinson, 1981, p. 19).

La teoría de G. Dorfles admitiría y diferenciaría en el proceso creador tres momentos sucesivos: una primera fase rítmico-imaginativa, todavía no expresada en conceptos ni hecha extrínseca en el peculiar medium de cada arte, una segunda fase sucesiva de organización e integración de estos primitivos esquemas rítmicos y una tercera fase final expresiva que los hace extrínsecos, este autor identificaría el ritmo con la auténtica imagen creadora, es decir, un esquema, un pattern que antes de traducirse en expresión poética, plástica o musical, vive como elemento rítmico-sonoro. Así Schiller sostenía que antes que el contenido conceptual de la poesía, se le presentaba el elemento rítmicosonoro de la misma. Mientras que Eliot decía que un poema podía tener una tendencia a construirse como ritmo particular antes de lograr su expresión en palabras y que es más bien ese ritmo el que puede llevar al nacimiento de la idea y la imagen.

Ejemplo de esto sería la obra de Escher, donde vemos mosaicos, figuras imposibles y composiciones que daban lugar a formas matemáticas que ni siquiera habían sido descubiertas cuando el artista las representó. Al parecer jamás formuló ninguna ecuación matemática que describiese la geometría de sus composiciones, sino que se adelantó a su tiempo revelando a través de su obra, las formas de estas geometrías todavía desconocidas por los matemáticos, éstos más tarde describirían con fórmulas matemáticas las composiciones a las que Escher llegó por intuición.

C. G. Jung atribuye a expresiones matemáticas de nuestro entendimiento la posibilidad de señalar realidades de tipo inaprensible, como las creaciones de la fantasía y los motivos arquetípicos: 
Hay ecuaciones matemáticas de las que se ignoran a qué realidad física corresponden; igualmente existen realidades míticas y en principio no sabemos a qué realidad psíquica se refieren. Así, por ejemplo, se han planteado ecuaciones que determinan la turbulencia de los gases al calentarlos, antes de que ello se hubiera investigado exactamente; desde hace mucho tiempo existen mitologemas que expresan el transcurso de ciertos procesos decrecientes que sólo actualmente podemos reconocer como tales...

El mito es el grado de transición inevitable e imprevisible entre el inconsciente y el conocimiento consciente. Se afirma que el inconsciente sabe más que la consciencia, pero es un saber de tipo especial, un saber en la eternidad casi siembre sin relación al Aquí y Ahora, al margen de nuestro lenguaje racional. (Jung, 1996, p. 317)

Para C. G. Jung la imaginación activa nos pondría en condiciones de descubrir los arquetipos: “... el arquetipo es justamente no sólo imagen en sí, sino al mismo tiempo <dinamis> que se manifiesta en la numinosidad y fuerza fascinadora de la imagen arquetípica" (Jung, 1994b, p. 156). Las representaciones arquetípicas que nos transmitirían lo inconsciente, no serían arquetipos en sí, sino que serían imágenes que variarían de forma y que en última instancia se remitirían "a una forma primordial, en sí no intuible" (Jung, 1994b, p. 158). Pone de ejemplo las infinitas variables del tema mandala:

Se trata de una forma primordial relativamente simple, cuya significación acaso puede ser expresada llamándola "central". Pese a que el mandala aparece como la estructura de un centro, queda incierto si dentro de la estructura está más acentuado el centro o la periferia, la división o el conjunto indiviso. (Jung, 1994b, p. 158)

L. Duch señala como en ningún sector de la existencia habría creatividad, si faltara la colaboración del símbolo, ya que la creatividad sería un acontecimiento dinámico que produciría un cambio y maduración en el ser humano. El símbolo como la creatividad habrían mantenido una estrecha relación, ya que el símbolo sería la manifestación plástica de "la creatividad poética, musical, convivencial, casi como si se tratara de una suerte de revelación" (Duch, 2003, p. 309). 


\section{La Imaginación como Elevadora de Nuestra Conciencia y su Relación con los Arquetipos}

Sri Aurobindo señala como el ser humano sería un centro de toda la consciencia universal, definiendo la consciencia como una fuerza del cosmos que estaría no sólo en el hombre, sino también en los animales, en las plantas y en las cosas inanimadas, explicando como la consciencia humana sería "una fuerza de existencia consciente-de-si en la que la mente sería un término medio" (Aurobindo, 2008, p. 121).

Para este autor el despertar de nuestra consciencia tendría que ver y estaría determinado por el equilibrio entre mente y materia que se produciría por la vida en su evolución. La consciencia tendría capacidad formativa y el poder no sólo de englobar, medir y limitar, sino que también sería "aquello que perfila mide y da forma a lo informe; introduce la psicología en lo Incognoscible y parece hacerlo cognoscible; da paso a la geometría de lo ilimitado y parece hacerlo mensurable" (Aurobindo, 2008, p. 137). Así el individuo creativo o aquel que es capaz de desarrollar "algo a partir de sí mismo hace una distinción entre él, la fuerza que actúa en él y el material en el que trabaja. En realidad, él mismo es la fuerza, el mismo es la consciencia individualizada de que se sirve, él mismo es el material que utiliza, él mismo es la forma resultante" (Aurobindo 2008, p. 151).

M. Bautista Pérez cree que nuestra imaginación al igual que nuestra actividad mental pueden estar induciendo no sólo a una cierta reorganización del funcionamiento de nuestro cerebro y de su fisiología, sino que también habría una potenciación, por lo que no descarta la hipótesis de que el desarrollo del cerebro humano a lo largo de nuestra historia se hubiese producido en cierta medida desde nuestra propia mente, frente a la idea de los neurocientíficos que postulan como el funcionamiento cerebral generaría el funcionamiento mental. De esta forma el funcionamiento mental como el cerebral interactuarían entre sí y no sólo se realimentarían a múltiples niveles, sino que se inducirían mutuamente cambios constantes, concluyendo este autor:

(...) que determinados cambios clave en las conexiones sinápticas podrían haber inducido cambios decisivos en el funcionamiento habitual de nuestra consciencia y, viceversa, determinados cambios acaecidos a nivel de nuestra consciencia habrían provocado cambios claves en el funcionamiento de nuestro cerebro. (Bautista Pérez, 2015, p. 246) 
M. Bautista Pérez cree que algunas de las diferencias cognitivas debieron influir de manera decisiva en la "velocidad" evolutiva e incluso en el tipo de evolución, mencionando el trabajo de Álvaro Pascual-Leone, director del Beth Israel Deaconess Medical Center, en la Facultad de medicina de Harvard (Estados Unidos) cuyos experimentos demostrarían que la imaginación puede cambiar nuestra anatomía cerebral:

Una de las razones por las que podemos cambiar nuestro cerebro sólo con la imaginación es que, desde un punto de vista neurocientífico, imaginar una acción y ponerla en práctica no son cosas tan distintas como parecen (...). Los escáneres cerebrales demuestran que cuando imaginamos una cosa y la hacemos se activan las mismas partes del cerebro. (como se citó en Bautista Pérez, 2015, p. 245)

Eric Kandel que recibió el Premio Nobel en el año 2000, fue el primero en demostrar como en nuestro aprendizaje las neuronas individuales alterarían su estructura y fortalecerían determinadas conexiones sinápticas, probando "que cuando desarrollamos recuerdos a largo plazo las neuronas cambian su forma anatómica y aumenta el número de sus conexiones sinápticas con otras neuronas" (Bautista Pérez, 2015, p. 245).

El físico de Oxford, Roger Penrose que sería una autoridad en la teoría de la relatividad de Einstein, afirma que serían los procesos cuánticos los que podrían explicar la consciencia del cerebro humano y como en el interior de una neurona existirían unas estructuras diminutas que llamó "microtúbulos", donde dominarían los procesos cuánticos. Según M. Kaku: "Penrose concluye que el cerebro es básicamente un dispositivo mecanocuántico y que hay problemas que ninguna máquina podrá resolver debido al teorema de incompletitud de Gödel. Sin embargo, los humanos podemos descifrar esos enigmas gracias a la intuición" (Kaku, 2014, pp. 437-438).

El catedrático ruso Konstantin Korotkov creador de una línea científica llamada electrofotónica, afirma como el artista puede llegar a un periodo de iluminación o estado alterado de consciencia que define como "EAC", explicando cómo este estado se manifestaría en la distribución de la actividad neuronal sobre la superficie del cerebro, así en el estado de vigilia normal se observaría actividad sólo en algunas áreas del cerebro, sobre todo frontales, mientras que en el estado alterado de conciencia, la actividad se distribuiría por toda la corteza cerebral y cubriría los dos hemisferios. "El cerebro comienza a funcionar en armonía en su conjunto, incluyendo todas sus estructuras en una sola sinfonía de ondas, lavando la superficie del cerebro, igual que las olas lavan las rocas costeras" (Korotkov, 2015, p. 164). 
Esta iluminación de la consciencia se caracterizaría por un estado especial de la actividad cerebral, corporal y energética donde el cerebro alcanzaría su estado más armónico:

La naturaleza de la actividad eléctrica del cerebro en el estado alterado de conciencia cambia en comparación con la condición o el sueño habitual. La baja frecuencia se suprime, el cerebro comienza a generar frecuencias mayores: betaactividad. Curiosamente, en el estado alterado de conciencia, la amplitud de las ondas cerebrales apenas depende de la frecuencia, y se aproxima a la sección áurea. (Korotkov, 2015, p. 164)

K. Korotkov dice como esta relación fue descubierta por los griegos siendo la base de la armonía entre la naturaleza y la arquitectura clásica. G. Dorfles nos introduce en esta geometría afirmando como los edificios sagrados de la Antigüedad como las pirámides o el templo griego tenían una numerosidad como la de la gama pitagórica, con significados ocultos que más tarde fue transmitido por los enigmas de la Cábala y del Hermetismo, a través del misticismo de los rosacruces y alquimistas. El principio esencial en la que se basaban estas enseñanzas era que los números no son únicamente el equivalente de relaciones particulares, sino entidades por sí mismos, modelos dotados de cualidades mágicas, de los cuales las cosas que nos circundan, ciencias, artes, no son otra cosa que imitaciones. La numerosidad de aquellas épocas respondía a razones precisas de carácter iniciatorio. El arte basado en una constante numérica fue legado por Grecia, desarrollándose con los pitagóricos y llegando más tarde hasta Vitruvio. Esto culminará en los estudios de Pacioli, de León Battista Alberti o Durero y así sucesivamente hasta Palladio, Cardano, Seamozzi, volviendo a ser investigado en el siglo XX por Mondrian, Bill, Chyka y Kayser:

La esperanza de poder encontrar la clave única e incorruptible que sirviera de passepartout para descifrar el misterio de la creación artística era tal, que época tras época los artistas y los investigadores de este tema creyeron haberla descubierto, ya en el Número de oro, ya en la serie de Fibonacci, ya en la repetición de "verdades" naturales: estructuras cristalinas, espirales vegetales, círculos, elipses, hipérbolas y parábolas, que reproducen el curso de los astros o las más escondidas estructuras orgánicas. (Dorfles, 1986, p. 62) 
E. Pérez de Carrera nos acerca a esta misteriosa geometría sagrada:

Se construyeron geometrías sagradas en base a números de longitud infinita. Espacios cabalizados con números transcendentes y medidas irracionales fueron cuna de nuevas músicas y nuevos estados, que pretendieron reproducir arquetipos de mundos interiores en los que el hombre se viera como una célula situada en un espacio en que las fuerzas telúricas y las líneas que rompen el aire provocaran sensaciones escondidas que alteran la consciencia. Se construyeron laberintos, configuraciones mandálicas que sirvieran de modelo a marchas y bailes rituales en los que jugaban las energías que ruedan por la Tierra (corrientes, absorciones, empujes, etcétera) en su relación con el Cosmos, y se orientaron en las rutas del Sol o en las del tiempo hacia momentos astronómicos especiales como los solsticios. (Pérez de Carrera, 2004, pp. 224-225)

R. Lawlor afirma que gracias a la identificación del individuo con las proporciones universales esenciales expresadas en la forma humana ideal, puede el hombre contemplar el vínculo que existe entre su propia fisiología y la cosmología universal (véase Figura 1), concibiendo así una relación con su propia naturaleza. El cuerpo humano contendría en sus proporciones todas las medidas y funciones geométricas y geodésicas importantes, de manera que este conjunto de proporciones universales dentro del cuerpo humano ideal se basaría en muchas culturas, en el canon que rige la métrica del canto y la poesía, los movimientos de la danza y las proporciones de la artesanía, el arte plástico y la arquitectura. Tanto el mundo aparencial como el subatómico, estaría lleno de formas y relaciones geométricas, que coincidirían con el movimiento, el ritmo y o la composición de la obra artística.

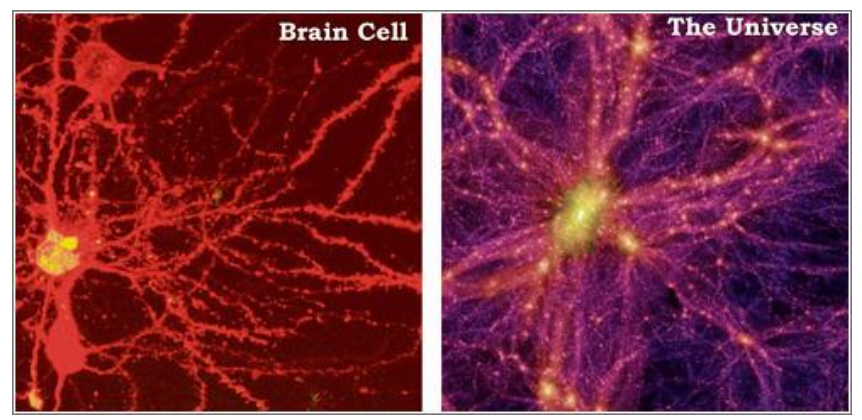

Figura 1. Similitud morfológica entre la red de neuronas del cerebro humano y la red cósmica. Recuperado de www.micr osiervos.com/images/celula-universo.jpg 
R. Lawlor pone de ejemplo los mosaicos semirregulares que permitirían dos tipos de vértice y formarían la base de los patronos constructivos de gran parte de las tradiciones de las artes sagradas y decorativas, como las decoraciones celtas e islámicas, apareciendo tanto en estructuras celulares como cristalográficas. El matemático Roger Penrose descubrió un mosaico compuesto solamente por dos formas de teselas con las que rellenar el plano, descubriéndose como estos mismos patrones subyace en la naturaleza de los líquidos, siendo intersecciones de estructuras de dimensiones superiores. Artistas contemporáneos se inspiran en este tipo de patrones como John F. Simon Jr. que se basará en el proceso que describe Klee en su Cuaderno pedagógico de 1925, donde el pintor explicaría sus intentos de estudiar las posibilidades combinatorias de esquemas y estructuras rellenando los cuadros de una cuadratura dibujada sobre papel. Simon hace una interpretación de esta experiencia de Klee en su obra Every Icon, un applet de Java (una pequeña aplicación que funciona dentro de un navegador) (véase Figura 2) que ejecuta este algoritmo: "Dado: un icono definido por una cuadrícula de 32x32. Permitido: todo elemento de la cuadrícula puede ser coloreado en blanco y negro. Mostrando: todo icono" (como se citó en Tribe y Jana, 1998, p. 30).

M. Tribe y R Jana definen esta obra de net art como un experimento intelectual, ya que la aplicación para acabar de dibujar todos los iconos posibles haciendo realidad la versión computacional de la cuadrícula de Klee. tendría tal número de combinaciones que este experimento se alargaría en cientos de trillones de años, incluso en un ordenador capaz de mostrar 100 iconos por segundo.

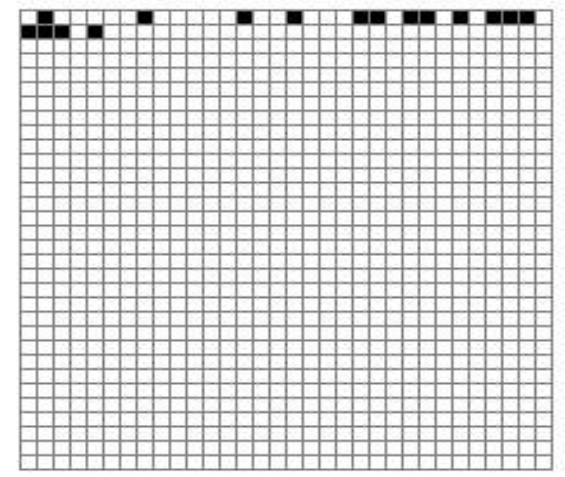

Figura 2. John F. Simon Jr. Every Icon. Recuperado de http://www.fondationlanglois.org/media/activites/ateliers/bio /John-F-Simon-Jr-Every-Icon.jpg 
Mary Heilmann emplea retículas y patrones geométricos inspirados en los motivos decorativos de las mantas mexicanas, como vemos en su obra abstracta Green Spiral de 1988, donde combinaría "la circularidad con la retícula minimalista en una espiral rectilínea que recuerda un laberinto" (Heartney, 2008, p. 70). En esta pintura el motivo de la espiral parece extenderse más allá del lienzo al igual que ocurre en muchos de sus patrones geométricos como en Saturday Night realizada en 1987 (véase Figura 3).

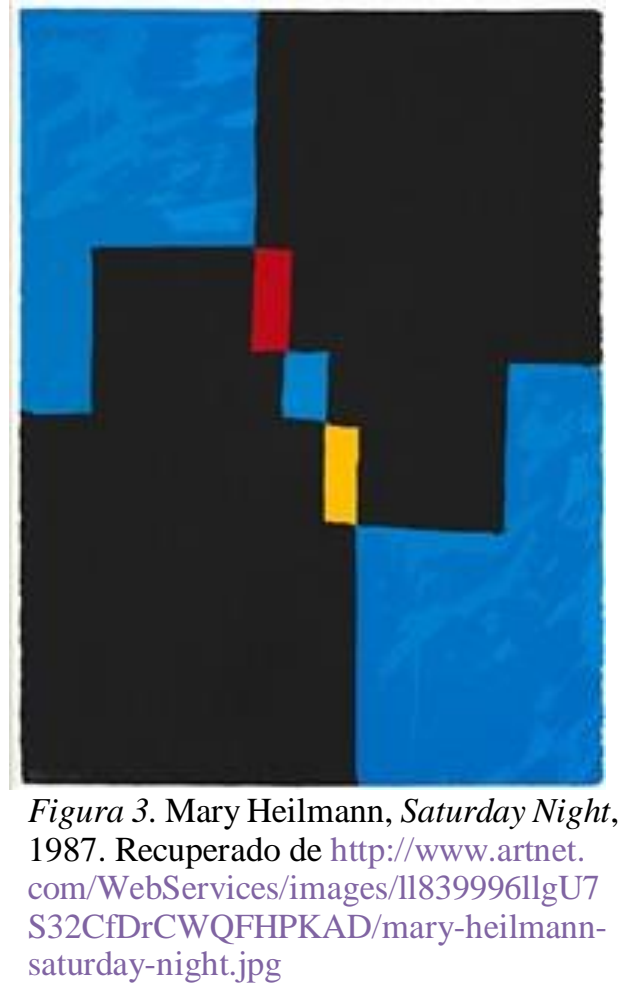

D. Maclagan llama la atención sobre este mismo hecho en las alfombras de lana de Usak, procedentes de Turquía Occidental del siglo XVIII (Imagen. 4), donde los motivos de la zona central tendrían los bordes recortados de un modo asimétrico y aparentemente arbitrario, dando la impresión de que el diseño se extendería más allá del borde: "Casi con seguridad, se trata de un artificio deliberado, con el que se pretende simbolizar el contraste entre la infinitud de Alá y los límites de la percepción humana” (Maclagan 1994, p. 32). 


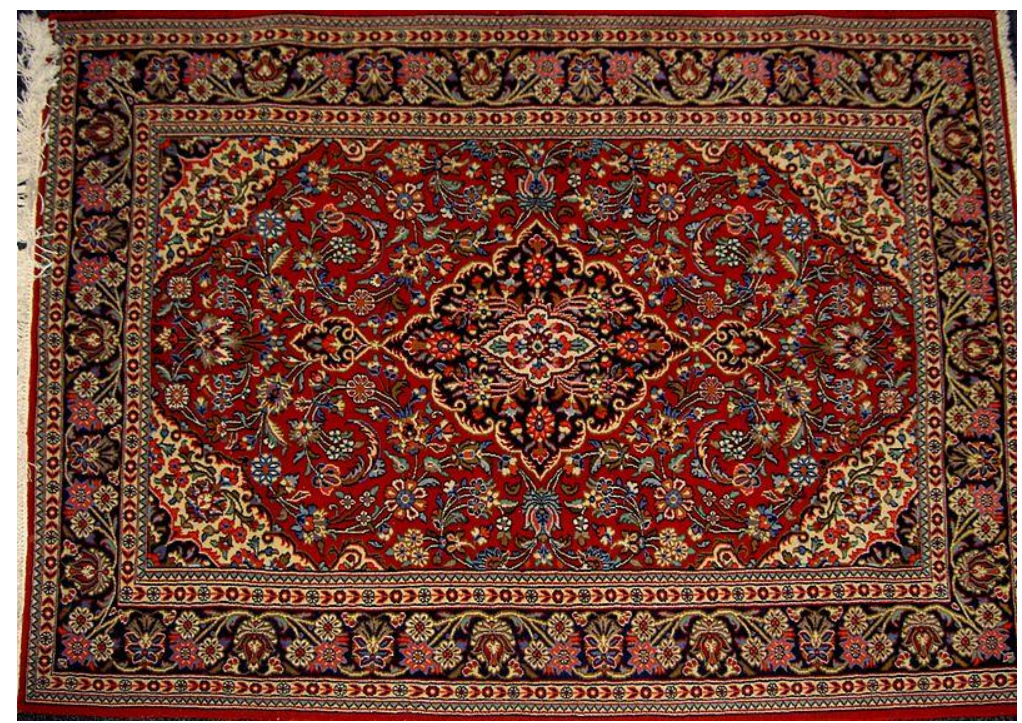

Figura 4. Alfombra de lana de Usak, Turquía Occidental, siglo XVIII. Recuperado de http://4.bp.blogspot.com/-8uZGYyJCK-k/UJfBcpRVtjI /AAAAAAAAA44/xXxv2yHSH4k/s1600/Alfombra+Qom.JPG

R. Lawlor señala como biológicamente, podemos recurrir a nuestras ideas sobre los códigos genéticos como vehículos de reproducción y continuidad, pero esta codificación no residiría en los átomos concretos, como el carbono, el hidrógeno, el oxígeno y el nitrógeno que compondrían la sustancia de los genes, del DNA, porque incluso estos átomos también están sujetos a un continuo cambio y sustitución. El vehículo de continuidad no sería sólo la composición molecular del DNA, sino también su forma helicoidal que sería responsable del poder reproductor del DNA. Según este autor la hélice que sería un tipo especial del grupo de las espirales regulares sería el resultado de una serie de proporciones geométricas fijas. Los artistas se inspiran en estos arquetipos universales que subyacen en nuestra naturaleza, así Robert Smithson en 1970 realizará una espiral de guijarros titula el Malecón en espiral en Great Salt Lake (Utah), donde la roca basáltica, los guijarros, el cieno, los cristales de sal, la tierra y el agua serían los verdaderos protagonistas, diciendo el artista de su obra:

Cuando descubrí este sitio, vibraba hasta el horizonte; parecía un cición inmóvil, y las vibraciones de la luz creaban la impresión de que todo el paisaje se agitaba (...) El espacio empezó a rotar, se encerró en sí 
mismo en un inmenso círculo. La posibilidad de Spiral Jetty surgió de este espacio en continuo giro. (como se citó en Lailach, 2007, p. 88)

El Premio Nobel de Física en 2004 y catedrático de Física en el Massachusetts Institute of Technology Frank Wilczek dice como la naturaleza sería inventiva en su lenguaje, ampliando la imaginación mediante nuevos tipos no sólo de números, sino también de geometría, e incluso de nuevos tipos de lógica en el mundo cuántico, diciendo que: "Cuando averiguamos que nuestro sentido de la belleza cobra realidad en el mundo, estamos descubriendo algo sobre el mundo, pero también sobre nosotros mismos" (Wilczek, 2016, p. 21).

F. Wilczek señala como la visión de Platón sobre los sólidos platónicos (véase Figura 5) anticiparía las ideas de vanguardia de nuestro pensamiento científico actual, explicando como la idea de que habría una simetría que subyace en la naturaleza habría dado lugar a una dominación de nuestra comprensión de la realidad física:

La inverosímil idea de que la simetría dicta la estructura -que se pueden usar requerimientos exigentes de perfección matemática para converger en una pequeña lista de posibles materializaciones, y luego usar la lista como un manual de construcción para nuestro modelo del mundo- se ha convertido, en los confines aún por cartografiar de lo desconocido, la estrella que nos guía. (Wilczek, 2016, p. 58)

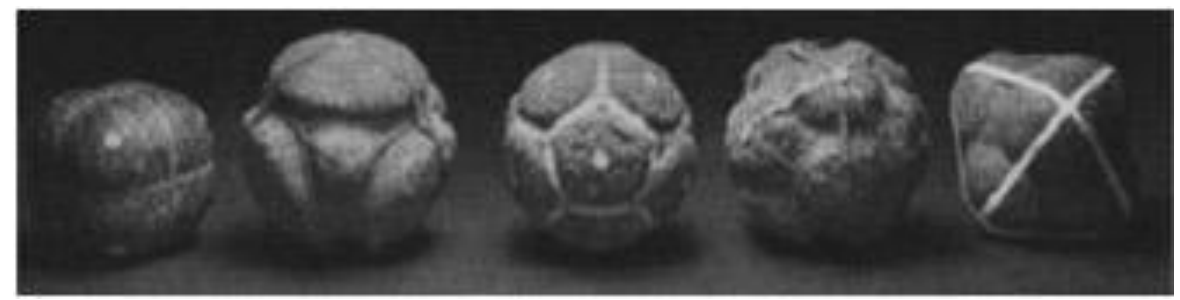

Figura 5. Los cincos poliedros regulares o sólidos platónicos representados en piedras esféricas talladas con formas geométricas del cubo, el tetraedro, el octaedro, el icosaedro y el dodecaedro. Neolítico. (Gran Bretaña) Ashmolean Museum de Oxford. Recuperado de http://files.cursoathenas.webnode.com.br/2000001699e6609f602/poli02.jpg

S. Hawking y L. Mlodinow afirman que la teoría de la relatividad general habría transformado la física en geometría. Diciendo como la física cuántica ya estaría planteando que la naturaleza actuaría a escalas atómicas y subatómicas, donde la posición, la trayectoria, el pasado y el futuro de los 
objetos, no estaría determinado con precisión, pudiendo estas teorías explicar también los acontecimientos relacionados con el ser humano y muestro entorno, ya que "somos estructuras compuestas, constituidas por un número inimaginable mente grande de átomos, mayor que el número de estrellas que hay en el universo" (Hawking y Mlodinow, 2010, p. 77).

La geometría nos ayuda a materializar verdades esenciales de nuestra naturaleza, percibiendo ritmos, movimientos y arquetipos que se esconderían en la materia, trascendiendo así nuestro estado actual, como nos evocaría E. Pérez de Carrera:

Los minerales, todas las formas cristalinas desde el diamante hasta el agua, han sido testigos y han formado parte de millones de vidas, $\mathrm{y}$ transitorios fracasos e infructuosos pulsos se han fotografiado y filmado en sus prismas. La atmósfera, la tierra, la luz, todo es una magnífica estructura de geometrías sagradas, un multimandala en latencia de memorias interfundidas. La vida no sería más que una suma de oportunidades para ir adquiriendo los lenguajes que pudieran descodificar planos de memoria que mostrarían realidades o secuencias diferentes desde lo referenciado y el referente. (Pérez de Carrera, 2004, pp. 272-273)

C. G. Jung nunca ha creído que nuestra percepción sea capaz de captar todas las formas del ser. Por esta razón afirma que el fenómeno de las creaciones arquetípicas descansaría en una forma de ser sólo condicionada psíquicamente, o de otras formas como las “espirituales” (Jung, 1996, p. 355), los arquetipos que preexisten a la consciencia y la condicionarían, aparecerían "como formas estructurales apriorísticas del fundamento instintivo de la consciencia" (Jung, 1996, p. 351). Estos arquetipos tendrían un lado que es accesible a la razón, pero también un lado que es inaccesible a esta por cuanto está compuesto no sólo de datos de naturaleza racional, sino también, de los datos irracionales de la pura percepción interna y externa. Hablan tanto al pensar, como al sentir y su peculiar carácter de imagen cuando se configura en una forma sensorial artística, estimularían tanto a la sensación como a la intuición. La obra artística adquiere así un contenido que impresiona, influye y fascina a través de una pre-forma inconsciente que parece pertenecer a la estructura heredada de la psique, y puede a causa de ello, manifestarse como fenómeno espontáneo en el proceso artístico.

Platón menciona la existencia de estas imágenes primordiales o primigenias, considerando su extraordinario valor de ideas metafísicas o paradigmas, con respecto a las cuales las cosas de la realidad se comportaban 
sólo como mimesis o imitaciones. Platón consideraba la geometría y los números como un lenguaje filosófico conciso, esencial e ideal, siendo un vehículo para la contemplación filosófica que se traduciría en el arquetipo, el cual tenía que ver con los procesos universales o modelos dinámicos que pueden considerarse independiente de cualquier estructura o forma material. En la filosofía medieval desde San Agustín (de quién C. G. Jung, tomó la idea de arquetipo, apareciendo también en Dionisio Aeropagita y en el Corpus Hermeticum) hasta Malebranche y Bacon, se movieron con relación a este tema en el mismo plano que Platón. Este último al igual que Pitágoras, tenían la intuición de que el mundo físico encarnaría conceptos bellos, siendo esta belleza la de la regularidad matemática y la simetría perfecta: "Ambos buscaban armonizar Mente y Materia mostrando que la materia se construye con los productos más puros de la Mente" (Wilczek, 2016, p. 57).

En este mismo sentido E. H. Gombrich dice como el estudio de la poesía se quedaría incompleto si no tiene conciencia del lenguaje de la prosa, de igual manera el estudio del arte tendría que completarse con una investigación de la lingüística de la imagen visual:

Entrevemos ya los contornos de la iconología, que estudia la función de las imágenes en la alegoría y el simbolismo, y su referencia a lo que podría llamarse el "invisible mundo de las ideas". El modo en que el lenguaje del arte se refiere al mundo visible es a la vez tan obvio y tan misterioso que todavía es desconocido en gran parte, excepto por los propios artistas, que saben usarlo tal como usamos todos los lenguajes, sin necesidad de conocer su gramática y su semántica. (Gombrich, 2002, p. 7)

C. G. Jung ya advirtió que nuestro espíritu no puede ser sólo un compendio de experiencias y percepciones del mundo, sino que, ciertas categorías de nuestro pensar estarían dadas a priori, esto es, antes de toda experiencia, apareciendo a la vez que el primer acto de pensar, e incluso serían condiciones preformadas de ese acto. La psique no sería al comienzo una "tabula rasa", como tampoco lo es el espíritu. Las posibilidades de contenido están dadas a priori por las disposiciones funcionales heredadas y preformadas. Según las teorías de este autor la psique sería el resultado de los modos de funcionar de los cerebros de la serie de los antepasados, un precipitado de las tentativas de adaptación y de las experiencias de la serie filogenética:

El nuevo cerebro o sistema funcional que se constituye es, por tanto, un instrumento antiguo, hecho para fines enteramente determinados, el 
cual no sólo apercibe pasivamente, sino que también pone orden activamente de por sí en las experiencias y las compele a dar ciertas conclusiones o juicios. (Jung, 1994a, p. 364)

Por lo tanto, estas ordenaciones no se producirían de forma arbitraria o por azar, sino que, se establecen mediante condiciones rigurosamente preformadas, siendo líneas directivas trazadas a priori que producen una determinada configuración a la materia de la experiencia. El inconsciente tendría una mentalidad de orden instintivo, careciendo de funciones diferenciadas, como el pensar, sino que simplemente crearía una imagen que respondería a la actitud consciente: "Esta imagen que contiene tanto pensar como sentir, y es cualquier cosa, pero nunca un producto racionalista de la reflexión. Tal imagen podría designarse más bien como una visión artística" (Jung, 1993, p. 80).

C. G. Jung dice que estas imágenes arquetípicas serían autóctonas y de uniformidad relativamente grande, apareciendo en las ciencias exactas como la raíz de conceptos indispensables, como la energía, el éter, o el átomo que serían intuiciones primitivas, una forma primordial de la energía sería "el mana y de la última el átomo de Demócrito y las chispas del alma de los primitivos habitantes de Australia" (Jung, 1995, p.160). Por lo tanto, el arquetipo sería un elemento formal, en sí vacío, una posibilidad dada a priori de la forma de la representación. No se heredarían las representaciones sino las formas, las cuales también están determinadas formalmente al igual que ocurre con los instintos. Jean-Paul Sartre en L ímaginaire (1940) dice: "No aceptaríamos una concepción según la cual la función simbólica haya de ser añadida a la imagen desde fuera. La imagen es esencialmente simbólica por su estructura misma" (como se citó en Giedion, 1991, p. 109).

El bioquímico Rupert Sheldrake que estudió en Cambridge sigue la misma línea de pensamiento cuando afirma que el ser humano recurriría a una memoria colectiva a la que contribuimos y como existirían unos "campos mórficos" que se constituirían por estructuras de pensamiento y experiencias comunes de muchos individuos del pasado: "Estos campos contienen algo parecido a las formas medias de la experiencia anterior definida en términos de probabilidad. Esta idea corresponde a la concepción de Jung sobre los arquetipos como <estructuras físicas innatas>" (Sheldrake, 2006, p. 388).

Esta memoria sería inherente a la naturaleza no sólo de los organismos vivos, sino que se produciría "en la naturaleza de cristales, moléculas y átomos y hasta en todo el cosmos" (Sheldrake, 2006, p. 13). Además, los campos mórficos estarían presentes en las sociedades, costumbres y hábitos mentales, 
siendo "patrones organizativos de influencia potenciales" (Sheldrake, 2006, p. 16). Aunque desaparezcan pueden volver a aparecer físicamente en otro lugar e incluso en otro tiempo, cuando se dan las condiciones físicas adecuadas:

Cuando vuelven a aparecer contienen en ellos mismos un recuerdo de sus existencias físicas anteriores. El proceso mediante el cual el pasado se hace presente en los campos mórficos se denomina resonancia mórfica. La resonancia mórfica conlleva la transmisión de influencias causales formativas que actuarían a través del tiempo y del espacio. (Sheldrake, 2006, p. 16)

Para este autor en el interior de los organismos en desarrollo, existiría una resonancia interna entre los campos de estructuras simétricas, siendo esencial esta autorresonacia para su simetría: "En los organismos vivos, esta autoestabilización de los campos mórficos puede ayudar a explicar cómo mantienen sus formas características a pesar de los continuos cambios de sus constituyentes químicos" (Sheldrake, 2006, pp. 210-211).

Alexander Gurvich a mediados de 1930 comenzaría a hablar sobre el concepto de campos bilógicos, según K. Korotkov este científico ruso decía que, además del nivel físico-químico, habría un sistema de campos distribuido en el espacio que estaría unido con cada objeto biológico. K. Korotkov dice como los puntos de acupuntura serían una proyección de los campos de onda cuánticos en la superficie de la piel: "Al mismo tiempo, a partir del principio de las estructuras de campo, es obvio que el campo se extienda fuera del cuerpo, en teoría a una distancia infinita” (Korotkov, 2015, p. 191).

\section{La Composición Artística y la Geometría como Encarnación de nuestra Naturaleza}

Para Platón los átomos serían las estructuras más básicas del mundo, constituyendo "encarnaciones de unos conceptos puros que pueden ser descubiertos y articulados por la Mente pura” (Wilczek, 2016, p. 59). Estas ideas fueron la base de la abstracción geométrica contemporánea que contemplaba nuestro mundo visible:

(...) como una pálida imitación de un conjunto de "formas" universales subyacentes. Al principio del siglo XX la teósofa rusa Madame Blavatsky y sus correligionarios que ejercieron un enorme ascendiente 
sobre los artistas vanguardistas de la época, trataron la naturaleza mística del color y la geometría invistiéndolos de un significado metafísico preciso. (Heartney, 2008, p. 66)

Estos arquetipos representarían funciones dinámicas que vincularían entre sí los mundos superiores y el proceso constante, junto con el mundo real de la materia, el arte en su búsqueda del orden espacial y la medición de las relaciones entre las formas sacaría a la luz estos símbolos que encarnan estructuras de la naturaleza reflejando procesos universales o modelos dinámicos del universo. R. Lawlor dice que los números que surgen de triángulo equilátero pitagórico $3,4,5$ produciría una simetría de gran belleza en las formas naturales: "Esta serie empieza con una expresión natural del triángulo equilátero y concluye con una serie de simetrías en que se inspiran las plantas de edificios en la arquitectura renacentista" (Lawlor, 1993, p. 43).

A Jaffé afirma que la frecuencia con que aparecen tanto el cuadrado y el círculo en el mundo del arte no debe desdeñarse, ya que, para esta autora:

Parece haber una ininterrumpida incitación psíquica para traer a la consciencia los factores básicos de la vida que ellos simbolizan. También, en ciertas pinturas abstractas de nuestros tiempos (que meramente representan una estructura coloreada o una especie de "materia prima"), esas formas aparecen, a veces, como si fuesen gérmenes de un nuevo crecimiento. (Jaffé, 1997, p. 250)

Tanto en la escultura como en la pintura estos arquetipos subyacerían en la composición de las grandes obras de arte de todos los tiempos, siendo este hecho mencionado por Kandinsky que dice cómo en el arte antiguo de los persas aparece la subordinación de la composición a una forma geométrica. El artista explica el planteamiento de la composición puramente pictórica con respecto a la forma hablando del arquetipo, al que Kandinsky llama "el elemento abstracto" (Kandinsky, 2010, p. 61), que se escondería tímidamente y era apenas visible en el pasado, habiéndose producido en su época un desarrollo y un predominio del "elemento abstracto" (Kandinsky, 2010, p. 61) o símbolo. "Porque cuanto más se hace retroceder la forma orgánica, tanto más pasa a primer plano y gana resonancia la forma abstracta" (Kandinsky, 2010, p. 61). Pone de ejemplo las Mujeres bañándose de Cézanne (véase Figura 6) que tienen una composición triangular, Kandinsky define este símbolo como “¡El triángulo místico!” (Kandinsky, 2010, p. 61), no siendo este triángulo un elemento solamente de apoyo para la armonización de la escena, sino el objetivo artístico expreso: 
La forma geométrica es al mismo tiempo medio para alcanzar la composición pictórica: el acento descansa sobre el objetivo puramente abstracto, actuando también con fuerza el elemento abstracto. Por eso Cézanne varía con toda razón las proporciones humanas: no sólo la figura total tiende al vértice del triángulo, sino que las partes de los cuerpos tienden hacia arriba, como impulsadas por un huracán interior, y se hacen cada vez más ligeras y alargadas. (Kandinsky, 2010, p. 61)

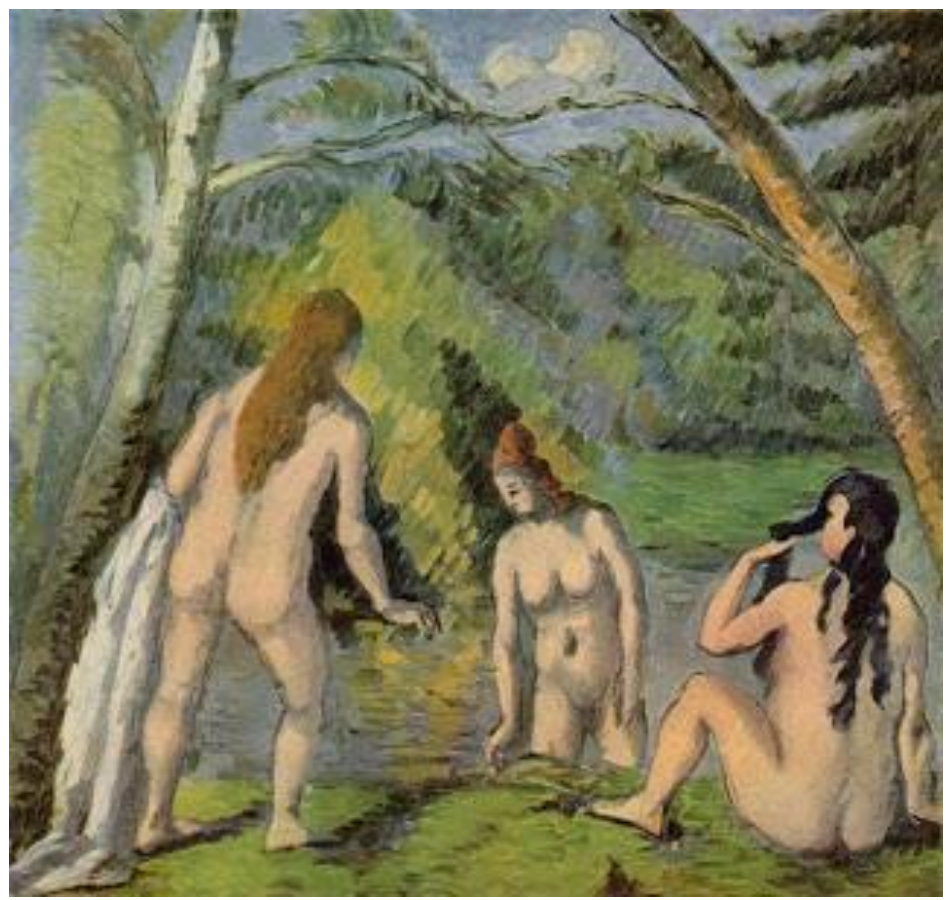

Figura 6. Cézanne, Tres bañistas, 1879-82, Petit Palais, Musée des Beaux-Arts de la Ville de Paris. Recuperado de http://2.bp.blogspot. com/_83sLmJ1QWf8/SqFReLhKydI/AAAAAAAAAuo/F6hlixZE ryw/s320/tres+bañistas,+1879-1882.jpg

Kandinsky señala como el ser humano tendería a lo más regular y al propio tiempo a lo más abstracto, poniendo el ejemplo del triángulo que habría sido utilizado como base constructiva, siendo el más empleado el triángulo equilátero. Para el artista la abstracción pura utilizaría elementos que dirigirían su existencia material, como haría el realismo puro. Llegando a la conclusión "de que el efecto externo puede ser distinto del interno; el efecto interno causado por la resonancia interna, la cual es uno de los más poderosos 
y profundos medios de expresión de toda composición" (como se citó en Giedion, 1991, p. 182).

En las composiciones pictóricas, el cuadrado es protagonista en multitud de épocas distintas, este arquetipo representaría la tierra, simbolizando la experiencia consciente de la existencia finita, de lo que ha nacido a la naturaleza, el cuadrado sería el símbolo de la finita perfección. R. Lawlor dice como la matemática pitagórica se limitaba a los números enteros, como estados definibles y detenidos que buscaban expresiones universales dentro del marco mensurable y geométrico del cuadrado explicando como la palabra naturaleza significa "lo nacido" y todo nacimiento a la naturaleza requeriría un cruce de contrarios:

Si cruzamos una vertical con una horizontal, dando a esas líneasmovimientos unidades de longitud iguales, digamos por ejemplo 4, vemos que ese cruce genera una superficie cuadrada: una entidad tangible y mensurable cobra existencia como resultado de un cruce. El cruce puede transferirse simbólicamente al cruce entre contrarios de cualquier tipo, tales como el cruce (...) de la materia y el espíritu que da origen a la vida misma. Por lo tanto, el cruce es una acción-principio que el cuadrado representa perfectamente. (Lawlor, 1993, p. 24)

El zen manifiesta armoniosamente la creación mediante la simple progresión desde la unidad del círculo, pasando por el triángulo, hasta la forma manifiesta del cuadrado (véase Figura 7).

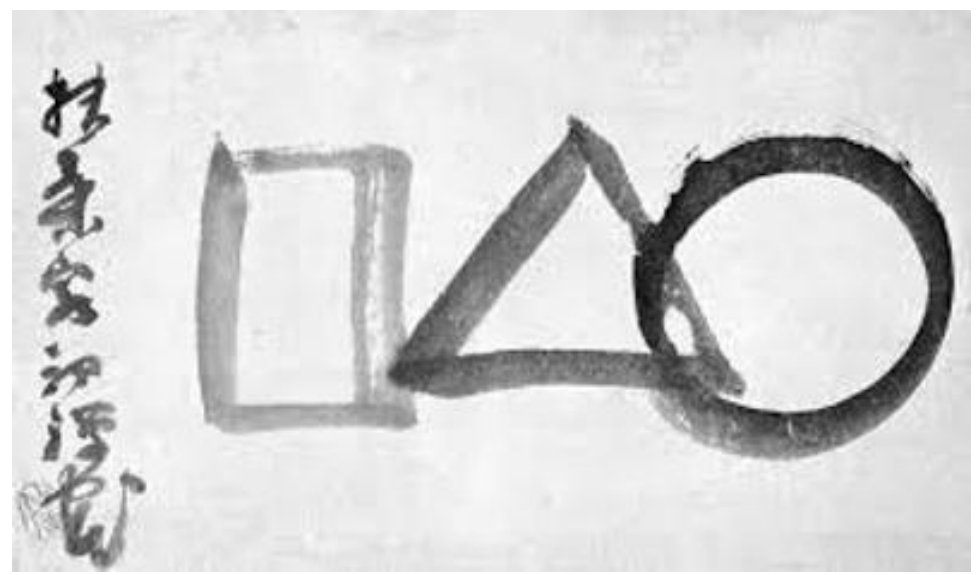

Figura 7. Dibujo caligráfico Zen. Recuperado de http://www.arsgra vis.com/wp-content/uploads/2015/10/pre.2.jpg 
En las obras de arte el cuadrado estaría en la zona inferior de la composición siendo también frecuente el rectángulo, símbolos de materia terrenal o plano de tierra, el círculo coronaría el espacio superior dejando en medio un espacio para el triángulo como intermediario entre los dos planos, cielo y tierra, de lo que se desprende que estas composiciones representarían al hombre cósmico como vemos en la escultura de Eduardo Paolozzi, El último ídolo de 1963 (véase Figura 8) o en la obra de Hilma af Klint, $N^{\circ} 4$, serie V de 1920 (véase Figura 9).

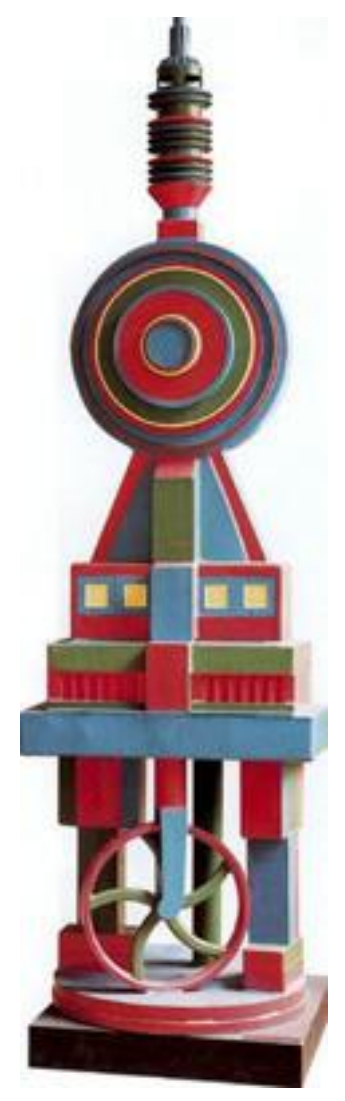

Figura 8. Eduardo Paolozzi, El último ídolo, 1963. Recuperado de http://files.tu-mundo60.web node.com.co/200000020-e6315 e7891/paolozzi1.jpg 


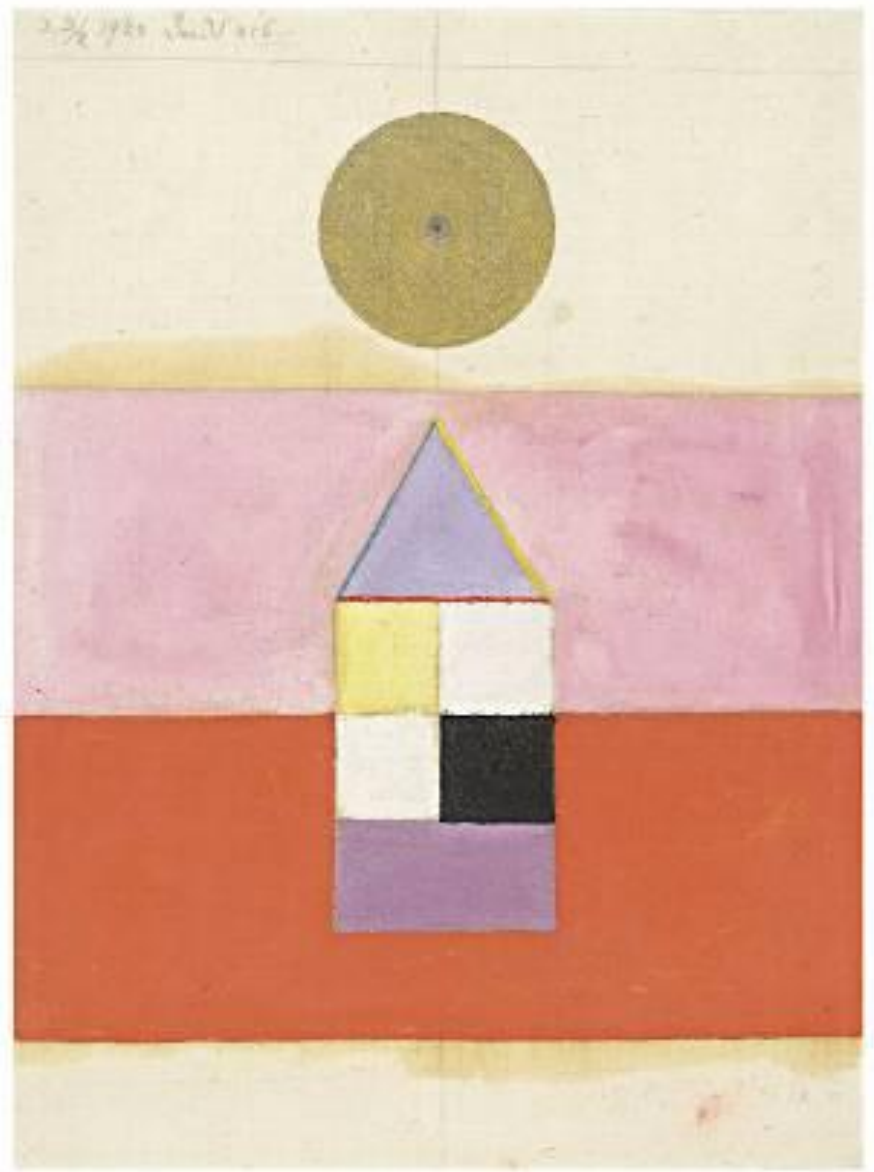

Figura 9. Hilma af Klint, $\mathrm{N}^{\circ}$ 4, serie V, 1920. Recuperado de http://maler.gallery/wp-content/gallery/af-klint/Hilma-af-KlintSerie-V-Nr-6.jpg

R. Lawlor señala como una de las aplicaciones del mandala en la arquitectura sería las cúpulas tanto islámicas como cristianas. El cuadrado que representa el plano de tierra abarca en un cuádruple abrazo por la bóveda circular del cielo que estaría sometida a la rueda del tiempo en perpetuo movimiento: 
Cuando el incesante movimiento del universo, representado por el círculo, da paso al orden comprensible, aparece el cuadrado. El cuadrado presupone pues al círculo y es resultado de éste. La relación entre forma y movimiento, espacio y tiempo, está evocada en el mandala. (Lawlor, 1993, p. 16)

Este tipo de mandala se emplea en el lamaísmo y el yoga tántrico como instrumento de contemplación, consistiría generalmente en un círculo alrededor o dentro del cual se encuentra un cuadrado u otra figura religiosa ricamente representada, así los mandalas que se encuentran en los templos del Tíbet serían utilizados como modelos de imaginación activa para la conformación de mandalas individuales, significando el cosmos en su relación con las potencias divinas (véase Figura 10).

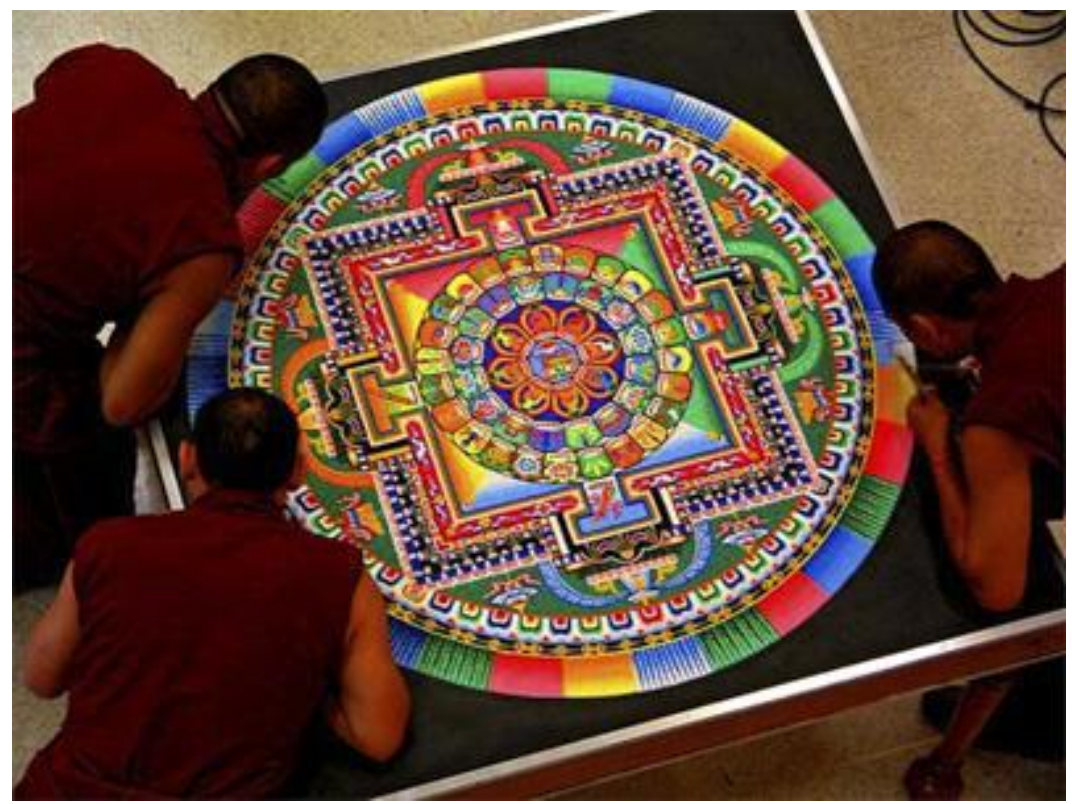

Figura 10. Monjes del Tíbet realizando un mandala. Recuperado de http://www.planetaholistico.com.ar/Tibet/budismo-tibetano-mandala2.jpg

F. Wilczek enlaza las teorías de la simetría y la luz del físico escocés James Clerk Maxwell con el arte del mandala, éste último desarrolló las ideas de Faraday bajo un formalismo matemático que explicaba la relación que había entre la electricidad, el magnetismo y la luz. Las ecuaciones de Maxwell describen los campos eléctricos y magnéticos, revelando estructuras de gran 
belleza, que se pueden observar mediante láseres monocromáticos brillantes. F. Wilczek pone el ejemplo de la sombra que proyectaría una cuchilla de afeitar, o cualquier objeto con un filo recto y agudo, iluminado con luz purificada: "Al magnificar la sombra proyectada por la luz purificada, descubrimos un patrón exquisito y hermoso" (Wilczek, 2016, p. 144).

Este autor dice como los átomos compartirían gracias a su mezcla de regularidad y variación, la cualidad de los mandalas, diciendo que las ecuaciones de los átomos y la luz serían los mismos que gobernarían tanto los instrumentos musicales como el sonido:

Nuestras Teorías Centrales de las cuatro fuerzas de la naturaleza gravedad, electromagnetismo y las fuerzas nucleares fuerte y débilencarnan en su médula un principio común: simetría local... este principio consuma y a la vez trasciende los anhelos de Pitágoras y Platón por la armonía y la pureza conceptual. (Wilczek, 2016, p. 19)

Según F. Wilczek este principio desarrollaría y transcendería la geometría artística de Brunelleschi, al igual que los descubrimientos de Newton y Maxwell sobre la naturaleza del color, llamando la atención de cómo ya Galileo decía como la Naturaleza estaba escrita en ese gran libro que está delante de los ojos, refiriéndose al universo, pero para entenderlo, había que aprender primero, el lenguaje y captar los símbolos en que está escrito: "El libro está escrito en lenguaje matemático, y los símbolos son triángulos, círculos y otras figuras geométricas, sin cuya ayuda resulta imposible comprender una solo palabra de él; sin las cuales uno merodea en vano por un laberinto oscuro" (como se citó en Wilczek, 2016, p. 20).

F. Wilczek relaciona las descripciones de la realidad física, en la teoría cuántica y en las cuatro Teorías Centrales de las fuerzas (gravitación, electromagnetismo, fuerzas fuerte y débil), en el simbolismo del yin y el yang. Relatando como Niels Bohr, uno de los científicos que fundó la teoría cuántica, concebía grandes "paralelos entre su concepto de la complementariedad y la dualidad unificada del yin-yang... Nuestras Teorías Centrales se basan en la interacción entre fluidos similares a la luz que llenan el espacio (yang) y sustancias (yin) a las que dirigen a la vez que responden" (Wilczek, 2016, p. 244).

La formulación que utiliza sobre el yin (materia) y el yang (fuerza) a la que considera como dualidad aparente, se podrían resolver en una unidad más profunda que define como la supersimetría (Wilczek, 2016, p. 245). La supersimetría, la simetría local que permite transformaciones que se producen independientemente en distintos lugares y tiempos, además de la teoría 
cuántica, serían "el fundamento de un intento atractivo de unificar y mejorar la Teoría Central de las cuatro fuerzas que resumen nuestro conocimiento de la naturaleza" (Wilczek, 2016, p. 427).

\section{Conclusiones}

La experiencia artística puede convertirse en una aproximación a la manera en que el ser humano como microcosmos se ordena y se sustenta en el mundo, siendo capaces de ver que la naturaleza puede revelar una continua e intemporal acción universal generalmente oculta a nuestra percepción sensorial y que el arte puede sacar a la luz, desarrollando así nuestras potencialidades, siendo el artista un elemento clave que acercaría al espectador a esta geometría que se esconde en la materia, y que se traduciría en el arte en símbolos y arquetipos.

El artista representaría las formas de la naturaleza intentando conocer a través de ellas las relaciones invariables que gobiernan e interrelacionan estas formas, poniendo al espectador en resonancia con el orden universal y elevando nuestros patrones de pensamiento a un nivel arquetípico que propiciaría la penetración de la fuerza de estos símbolos en nuestra consciencia.

\section{Referencias}

Aurobindo, Sri. (2001). El secreto del Veda. Tomo I, Barcelona: Fundación Centro Sri Aurobindo.

Aurobindo, Sri. (2008). La vida divina. Tomo I, Barcelona: Fundación Centro Sri Aurobindo.

Bautista Pérez, M. (2015). La paradoja de Darwin o el enigma del Homo sapiens. Córdoba: Col. Divulgación Científica, Guadalmazán.

Chipp, H. B. (1995). Teorías del arte contemporáneo, Fuentes artísticas y opiniones. Madrid: Col. Fuentes de Arte 12, Akal,

Dorfles, G. (1986). El devenir de las artes. México: Breviarios del Fondo de Cultura Económica.

Duch, L. (2003). Antropología de la vida cotidiana. Simbolismo y salud. Madrid: Trota.

Giedion, S. (1991). El presente eterno: los comienzos del arte. Madrid: Col. Alianza Forma $n^{\circ}$ 16, Alianza Editorial.

Gombrich, E. H. (1999). El sentido del orden. Estudio sobre la psicología de las artes decorativas. Madrid: Debate. 
Gombrich, E. H. (2002). Arte e ilusión. Estudio sobre la psicología de la representación pictórica. Madrid: Debate.

Hawking S. y Mlodinow, L. (2010). El gran diseño. Barcelona: Crítica.

Heartney, E. (2008). Arte hoy. Barcelona: Phaidon Press Limited.

Jung, C. G. (1993). Las relaciones entre el yo y el inconsciente. Barcelona: Col. Biblioteca de Psicología Profunda no 114, Paidós.

Jung, C. G. (1994a). Tipos psicológicos. Barcelona: Edhasa.

Jung, C. G. (1994b). Arquetipos e inconsciente colectivo. Barcelona: Col. Biblioteca de Psicología Profunda n ${ }^{\circ}$ 14, Paidós.

Jung, C. G. (1995). Energética psíquica y esencia del sueño. Barcelona: Col. Biblioteca de Psicología Profunda ${ }^{\circ} 78$, Paidós.

Jung, C. G. (1996). Recuerdos, sueños, pensamientos. Barcelona: Col. Biblioteca Breve, Seix Barral.

Jung, C. G. Von Franz, M. L. Henderson, J. L. Jacobi, J. y Jaffé, A. (1997). El hombre y sus símbolos. Barcelona: Col. Biblioteca Universal $\mathrm{n}^{\circ} 3$, Caralt.

Kaku, M. (2014). El futuro de nuestra mente. El reto científico para entender, mejorar, y fortalecer nuestra mente. Barcelona: Debate.

Kandel, E. R. (2013). La era del inconsciente. La exploración del inconsciente en el arte, la mente y el cerebro. Barcelona: Paidós.

Kandinsky, V. (2010). De lo espiritual en el arte. Barcelona: Col. Paidós Estética $\mathrm{n}^{\circ} 24$, Paidós Ibérica.

Korotkov, K. (2015). La energía de la consciencia. Barcelona: Ediciones Obelisco.

Lailach, M. (2007). Land Art. Bonn: Taschen.

Lawlor, R. (1993). Geometría Sagrada. Madrid: Debate.

Maclagan, D. (1994). Mitos de la creación. La aparición de hombre en el mundo. Madrid: Debate.

Mitchinson, D. (1981). Henry Moore. Escultura. Barcelona: Polígrafa.

Pérez de Carrera, E. (2004). 49 Respuestas a la aventura del pensamiento. Tomo I. Madrid: Fundación Argos.

Sheldrake, R. (2006). La presencia del pasado. Resonancia mórfica y hábitos de la naturaleza. Barcelona: Kairós.

Tribe, M. Jana, R. (1998). Arte y nuevas tecnologías. Uta Grosenick: Taschen. Wilczek F. (2016). El mundo como obra de arte. En busca del diseño profundo de la naturaleza. Barcelona: Crítica. 
Mónica Álvarez Font: Profesora Titular del Departamento de Escultura e História de las Artes Plásticas. Universidad de Sevilla.

Email address: belenleon@us.es

Contact Address: Facultad de Bellas Artes. C/Laraña n³, CP 41003, Sevilla. 